\title{
Biossegurança em DST/AIDS: condicionantes da adesão do trabalhador de enfermagem às precauções*
}

\author{
BIOSAFETY IN STD/AIDS: CONDITIONERS OF NURSING WORKERS' \\ ADHERENCE TO PRECAUTION MEASURES \\ BIOSEGURIDAD EN ETS/SIDA: CONDICIONANTES DE LA ADHESIÓN DEL TRABAJADOR DE
ENFERMERÍA A LAS MEDIDAS DE PRECAUCIÓN
}

Elucir Gir ${ }^{1}$, Renata Ferreira Takahashi' ${ }^{2}$, Maria Amélia Campos de Oliveira ${ }^{3}$, Lucia Yasuko Izumi Nichiata ${ }^{4}$, Sueli Itsuko Ciosak ${ }^{5}$

\begin{abstract}
RESUMO
Visando identificar os condicionantes da adesão do trabalhador de enfermagem às precauções/isolamento na assistência, realizou-se este estudo do tipo descritivo tendo como população alvo enfermeiros representantes de hospitais de médio e grande portes da cidade de São Paulo. Das 79 instituições que se enquadravam nos critérios deter-minados, 15 (18,98\%) constituíram a amostra. Em reunião coletiva, utilizou-se a técnica de grupo focal para a coleta dos dados sendo as discussões gravadas em fita cassete, mediante consentimento dos participantes $e$, posteriormente, transcritas. Organizaram-se os dados segundo Bardin (1977), extraíram-se os núcleos temáticos e definiram-se duas categorias de análise empíricas, denominadas condicionantes institucionais e individuais.
\end{abstract}

\section{PALAVRAS-CHAVE:}

Segurança. Síndrome de imunodeficiência adquirida. Hepatite. Precauções universais. Enfermagem.

\author{
ABSTRACT \\ Aiming to identify the \\ conditioning factors of nursing \\ workers' adherence to \\ precaution/isolation in \\ caregiving, this descriptive \\ study was conducted with the \\ target population consisted \\ of nurses representing \\ medium-sized and large \\ hospitals in the city of \\ Sao Paulo. Of the 79 \\ institutions that met the \\ established criteria, 15 \\ (18.98\%) comprised the \\ sample of the study. \\ In a collective meeting, the \\ focal group technique was \\ used for data collection. After \\ obtaining the participants' \\ consent, discussions were \\ recorded on cassette tapes \\ and then transcribed. Data \\ was organized as proposed by \\ Bardin (1977), thematic units \\ were extracted and two \\ empirical analysis categories \\ were defined, which were \\ termed institutional and \\ individual conditioners.
}

KEYWORDS:

Safety. Acquired Immunodeficiency Sindromes. Hepatitis. Universal Precautions. Nursing.

\section{RESUMEN}

Teniendo como objetivo identificar los factores que condicionan la adhesión del trabajador de enfermería a las medidas de precaución/ aislamiento en la atención de enfermería, se realizó este estudio descriptivo que tuvo como blanco a enfermeros representantes de hospitales de mediano y gran tamaño de la ciudad de São Paulo. De las 79 instituciones que se encuadraban en los criterios determinados, 15 de ellas (el 18,98\%) constituyeron la muestra. En una reunión colectiva, se recopilaron los datos utilizándose la técnica del grupo focal, las discusiones fueron grabadas en una cinta casset, con el consentimento de los participantes $y$, posteriormente fueron transcriptas. Los datos se organizaron según Bardin (1977) y se extrajeron los núcleos temáticos definiéndose dos categorías de análisis empíricos, denominadas condicionantes institucionales e individuales.

\section{PALABRAS CLAVE:}

Seguridad. Síndrome de immunodeficiencia adquirida. Hepatitis. Precauciones universales. Enfermería.

\footnotetext{
* Este artigo é parte de um Projeto subsidiado pela FAPESP Processo 97/3514-0

1 Livre Docente, Professor Associado junto a Escola de Enfermagem de Ribeirão Preto Universidade de São Paulo.Departamento de Enfermagem Geral e especializada: egir@eerp.usp.br

2 Professor Doutor, junto a Escola de Enfermagem da Universidade de São Paulo (EEUSP). Departamento de Enfermagem em Saúde Coletiva.rftakaha@usp.b

3 Professor Doutor, junto a EEUSP. Departamento de Enfermagem em Saúde Coletiva. macampos@usp.br

4 Professor Doutor, junto a EEUSP. Departamento de Enfermagem em Saúde Coletiva. izumi@usp.br

5 Professor Doutor, junto a EEUSP. Departamento de Enfermagem em Saúde Coletiva. siciosak@usp.br
} 


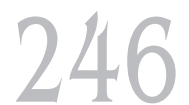

Rev Esc Enferm USP 2004; 38(3): 245-53.

\section{INTRODUÇÃO}

O recrudescimento de enfermidades que se encontravam sob controle, a identificação de novos microrganismos e a sua disseminação em áreas antes geograficamente circunscritas fazem com que as doenças infecciosas alcancem lugar de destaque entre os processos mórbidos que atingem o ser humano, até mesmo nos países desenvolvidos ${ }^{(1)}$.

Inúmeros esforços têm sido despendidos na busca de meios para diminuir os riscos de transmissão de doenças não passíveis de prevenção por meio de imunológicos, como a hepatite $\mathrm{C}$ e a aids, assim como para a proteção dos profissionais e usuários dos serviços de saúde, através de alterações da prática profissional visando minimizar os riscos contínuos de contaminação a que estes estão expostos e evitar a disseminação de microorganismos pelos diferentes modos de transmissão ${ }^{(1-4)}$.

No atendimento ao paciente, muitas vezes é impossível identificar com segurança e rapidez o seu estado de portador e as probabilidades de transmissão, fato que evidencia. que no momento da assistência, qualquer pessoa deve ser vista como potencialmente infectada, o que demanda adoção de medidas especiais para a proteção dos trabalhadores da saúde. Assim, a adoção de normas de biossegurança no trabalho em saúde é condição fundamental para a segurança dos trabalhadores, qualquer que seja a área de atuação, pois o risco de contaminação está sempre presente, ao redor de $0,3 \%$ para infecção pelo vírus da imunodeficiência humana (HIV), após exposição percutânea ao sangue contaminado, podendo chegar a 1 ou $2 \%$ no caso dos cirurgiões e trabalhadores de serviços de emergência ${ }^{(5)}$. A situação é ainda mais alarmante no caso da hepatite $\mathrm{B}$, pois o risco da aquisição do vírus é estimado em até $30 \%$, quando nenhuma medida profilática é adotada ${ }^{(6)}$. Estudos têm demonstrado que a contaminação de profissionais pelo HIV em acidentes pode ser evitada se forem adotadas medidas de biossegurança $\mathrm{a}^{(7)}$.

Nos Estados Unidos, a infecção pelo HIV ficou caracterizada como ocupacionalmente adquirida por 57 trabalhadores da Saúde ${ }^{(8)}$. O Brasil já tem confirmado o primeiro caso de aids conseqüente à exposição ocupacional ${ }^{(9)}$.
Para a enfermagem, esse risco é muito mais preocupante, pois o contingente da força de trabalho em saúde é bastante numeroso, prestando, na maioria da vezes, cuidados que envolvem o contato direto com o doente $^{(10-12)}$.

Ao longo do tempo, a adoção das medidas de biossegurança nas atividades profissionais tem sido um desafio para a enfermagem. Todos aceitam teoricamente as normas de biossegurança, no entanto, elas ainda não permeiam a prática diária com a mesma intensidade. Valores diferenciados são atribuídos ao risco de infecção conforme a categoria profissional, a atividade executada e o tempo de experiência na assistência a pacientes considerados "de risco", de modo que, mesmo havendo consenso quanto à existência do risco, ele não se aplica ao "tipo" de risco $^{(4)}$.

Apesar da potencialização do risco de exposição dos trabalhadores de enfermagem, temos observado que a adesão às medidas de proteção recomendadas é, por vezes, descontínua e até contraditória.

Sendo assim, realizamos este estudo com o objetivo de identificar os condicionantes da adesão do trabalhador de enfermagem às precauções/isolamento na assistência. É indiscutível a necessidade desta investigação, considerando-se o risco a que o profissional de saúde se expõe em termos da contaminação pelos vírus causadores das hepatites $\mathrm{B}, \mathrm{C}$ e aids.

\section{METODOLOGIA}

Constituiu-se população alvo deste estudo enfermeiros, chefes de unidades ou membros da Comissão de Controle de Infecção Hospitalar (CCIH), representando um total de 79 instituições hospitalares pertinentes ao município de São Paulo - Divisão Regional de Saúde I (DIR-I). A escolha das instituições obedeceu aos seguintes critérios: o hospital deveria estar listado no Relatório de Leitos Hospitalares da Secretaria de Estado da Saúde, do ano de 1999, pertencer ao município de São Paulo (DIR-1), estar em atividade e ser de médio (51 a 150 leitos) ou grande (151 a 500) porte. Quanto aos profissionais de saúde, estes deveriam participar efetivamente de uma reunião agendada para a coleta de dados. 
Por meio de contato telefônico e solicitação por ofício, obtivemos a aquiescência inicial de 35 instituições, das quais dez se fizeram representar, indicando enfermeiras como participantes da investigação.

Para a coleta de dados realizamos uma reunião com essas enfermeiras, utilizando a técnica do grupo focal e tendo como cerne da discussão os tipos de isolamento/precauções e os determinantes dessa prática. Empregamos essa técnica por ela possibilitar a reflexão crítica do tema abordado e por mostrar-se eficaz e pertinente, visto que proporcionou o enriquecimento da discussão e a emergência de aspectos concretos sobre a problemática em questão. Gravamos as entrevistas em fitas cassetes, mediante consentimento dos participantes, as quais foram posteriormente transcritas pelo pesquisador, que também organizou os dados ${ }^{(13)}$. Após a leitura exaustiva das falas, extraímos os núcleos temáticos, definindo duas categorias de análise, denominadas de "condicionantes institucionais" e "condicionantes individuais".

\section{RESULTADOS E DISCUSSÃO}

Através do grupo focal, a reflexão sobre a prática do isolamento/precauções possibilitou não apenas elencar os dados quantitativos, mas também conferir-lhes qualidade, o que poderá ser evidenciado nas transcrições a seguir, representativas das falas dos participantes.

Evidenciamos que a análise da prática do isolamento/precauções, nas instituições estudadas, permitiu identificar diferentes práticas, muitas vezes, distintas das recomendações emitidas pelas instituições governamentais responsáveis pela normatização do controle da infecção hospitalar.

Tal diversidade é, de certa maneira, esperada face à existência de poucos estudos sobre a eficácia das recomendações oficiais, no que diz respeito à prevenção da disseminação dos agentes etiológicos entre os pacientes, destes para os trabalhadores da área de saúde e vice-versa ${ }^{(14)}$.

Um aspecto interessante foi a constatação de que a prática do isolamento/precauções em instituições públicas é diferente da realizada em algumas instituições privadas. A maior disponibilidade de recursos materiais e

a possibilidade de punição do funcionário que não cumprir as normas estabelecidas, na instituição privada foram referidas como causas de tal diferença, conforme a fala de uma enfermeira:

\begin{abstract}
No hospital privado a quantidade de materiais existente é diferente e o funcionário segue as orientações do isolamento, senão a chefia o dispensa, não porque está visando o seu bem-estar, mas porque não quer problemas com o paciente e nem com o convênio de saúde...
\end{abstract}

Além de ser diversa, essa prática caracteriza-se como inadequada face às mudanças do cenário epidemiológico das doenças transmissíveis, pelo aparecimento de novas doenças e o recrudescimento de outras, além da evolução do conhecimento científico e da disponibilidade de novos recursos tecnológicos capazes de conferir uma melhor proteção ao trabalhador da área de saúde.

Assim, a despeito da evolução das recomendações oficiais e apesar das práticas mencionadas terem sido reformuladas pelos órgãos, algumas participantes do grupo focal mencionaram que as instituições a que estão vinculadas ainda adotam alguns procedimentos ultrapassados. Para ilustrar, citamos o caso das precauções universais, cuja recomendação foi revista, sendo o seu espectro de ação ampliado e a sua denominação modificada para precauções -padrão. Pudemos constatar a interpretação equivocada do seu conceito, na seguinte fala:

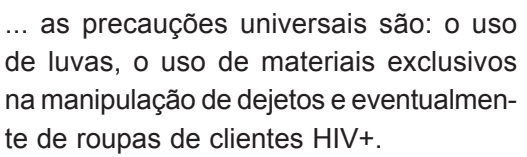

A proposta de formulação de uma política sobre as precauções/isolamento para as doenças transmissíveis tem como um de seus objetivos a elaboração de uma nova terminologia a fim de evitar interpretações errôneas. Atualmente, utilizam-se expressões como precauções - padrão, que podem levar a equívocos de interpretação dada a recomendação das precauções universais.

Na parte inicial da reunião, emergiram algumas características da prática de precauções/isolamento, que subsidiaram a compreensão dos condicionantes da adesão às precauções. A análise posterior permitiu reconhecer condicionantes que foram agrupados em duas categorias, reunindo uma delas os
Biossegurança em DST/AIDS:

condicionantes da adesão do trabalhador de enfermagem às precauções 
Elucir Gir

Renata Ferreira Takahashi

Maria Amélia C. de Oliveira Lucia lasuko Izumi Nichiata Sueli Itsuko Ciosak

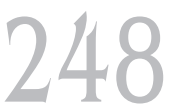

Rev Esc Enferm USP 2004; 38(3): 245-53. elementos relacionados à instituição e a outra, aqueles que mantinham uma aproximação maior com o profissional.

A categoria denominada condicionantes institucionais incluiu temáticas referentes à existência de supervisão, a rotinas sobre o uso de precauções/isolamento, a programas de educação continuada, a condições e disponibilidade de recursos materiais, além de fatores estruturais. Dentre estes fatores destacam-se a fonte de informação, a dificuldade de acesso e a falta de revisão/desatualização de normas/recomendações sobre a prática das precauções.

Em relação à fonte de informação que orienta a prática de isolamento/precauções em hospitais, o grupo considerou de competência dos representantes do Ministério da Saúde, e de fundamental importância, a elaboração e a divulgação de um manual que normatize as ações dessa prática, destacando a necessidade de um rápido e efetivo acesso ao mesmo.

\section{...devem existir normas oficiais que esta- beleçam as medidas básicas para orien- tar a prática. \\ ...é uma dificuldade grande para obter in- formação; ela só chega nos grandes cen- tros; há lugares que ninguém nem ouviu falar do CDC, a divulgação é falha.}

A dificuldade de acesso foi mencionada como entrave à prática diversificada, conforme podemos constatar na fala a seguir:

a periferia de São Paulo, o interior dos Estados, trabalham diferentemente dos grandes centros; as instituições mais centrais, que estão próximas às Universidades, têm acesso à informação atualizada.

Em relação à normatização, os participantes reconhecem que a orientação oficial disponível sobre a prática em questão está desatualizada, como mostra este depoimento:

... a última orientação sobre o isolamento em doenças contagiosas é muito antiga, é de 1984, não se tem nada recente, está completamente desatualizada.

A falta de atualização das normas regidas por portarias de órgãos governamentais competentes dificulta o acompanhamento do avanço científico e a atualização das práticas, contribuindo para a sua diversidade:
... tem que se embasar em alguma norma; só que hoje cada um faz ao seu modo, pois não há uma norma geral, é necessário uma referência.

A diversidade de nomenclatura encontrada pode também justificar o descompasso de conhecimento entre algumas participantes do estudo.

A co-existência de categorias de isolamento definidas em épocas diferentes, cuja aplicação destinava-se às mesmas doenças, resulta provavelmente da falta de clareza na definição e indicação dos tipos de isolamento, pois não se sabia corretamente quais fluidos e substâncias corpóreas exigiam uma ou outra categoria. Exemplificando, em 1985 foram introduzidas as "precauções universais" e em 1987 o "isolamento por substâncias corpóreas” (ISC) que excluía as categorias anteriores; ambos faziam recomendações semelhantes para prevenir a transmissão de microorganismos através do sangue, mas diferiam sobre a lavagem de mãos após a retirada das luvas ${ }^{(14)}$.

Foram referidas como integrantes da problemática em foco, a inexistência de normas e rotinas intra-institucionais, a inexistência ou a má qualidade tanto da supervisão dos trabalhadores da área de enfermagem como de programas de educação continuada, dificultando ou inviabilizando uma prática adequada.

É fundamental desenvolver um sistema organizacional visando assegurar o ensino das precauções aos profissionais, aos pacientes e aos visitantes, assim como o comprometimento da adesão às mesmas ${ }^{(14)}$. É igualmente importante a avaliação constante da adesão, o seu aperfeiçoamento e adaptações para atender às necessidades circunstanciais. Assim, torna-se essencial a reformulação das medidas expressas nas recomendações, em função das necessidades e das circunstâncias locais, considerando-se sobretudo a situação epidemiológica atual. No grupo, foi consenso a necessidade de adaptar as recomendações dos CDCs, considerando-se as realidades locais, pois nem todas as ações preconizadas são viáveis, dadas as diferentes características das instituições de saúde, especialmente em função da situação epidemiológica vigente e dos recursos tecnológicos disponíveis, tal como é indicado neste discurso: 
o que o CDC recomenda não é o que vemos na prática, elas são adaptadas(...); por exemplo, no caso de uma tuberculose, o máximo que conseguimos foi a colocação de molas mecânicas nas portas, para mantê-las fechadas; fluxo laminar, nem pensar?

Além disso, ocorrem adaptações tão amplas que, embora sejam fundamentadas nos mesmos princípios, configuram-se como modalidades distintas das recomendadas, como é o caso de um hospital que criou quatro tipos de isolamento identificados por números. Cada número designava situações referentes aos aspectos clínicos do agravo à saúde e à paramentação necessária. Verificamos, em tais casos, que o uso de EPI é definido pela fase clínica da infecção e não somente pela forma de transmissão.

As depoentes reconhecem, portanto, que a heterogeneidade das práticas pode ser minimizada se as diretrizes governamentais sobre as precauções/isolamento forem revisadas periodicamente e divulgadas para as instituições de saúde. Reconhecem ainda, que essas diretrizes devem nortear a elaboração de rotinas sobre tais práticas, levando em conta as adaptações necessárias para a realidade local.

Por outro lado, o relato de situações envolvendo recursos materiais permitiu que identificássemos que sua interferência na prática de precauções/isolamento não se restringe à insuficiência de materiais, mas também à sua qualidade, localização e disponibilidade, o que pode ser constatado nas seguintes falas:

Eles dizem, olha, já que ontem a gente passou sem luva e sem máscara e tive que tirar sangue, cuidar do doente, já tive contato(...)então hoje que tem, eu não vou usar! (...)se eu não peguei nada antes, não vou pegar hoje também. Tem exceção, mas a maioria é assim!

A qualidade do material também influencia (...)só depois de duas ou três tentativas que você consegue colocar as luvas, porque elas rasgam, aí a pessoa perde o estímulo.

... o pessoal recebe treinamento mas, quando chega na hora da prática, não há recursos materiais suficientes e adequados para aplicar o que aprendeu. A gente não tem nem como "cobrar" do funcionário, nem nós conseguimos aplicar o que foi ensinado.
As depoentes culpam, em parte, a instituição pela prática inadequada das precauções/isolamento devido a falta de condições mínimas para uma prática efetiva. A arquitetura hospitalar também foi citada como um fator que dificulta essa prática.

A categoria condicionantes individuais envolveu temáticas que dizem respeito ao reconhecimento ou não da vulnerabilidade da instituição à infecção, a formação do profissional e ao significado atribuído às precauções/isolamento.

Os comentários das integrantes do grupo confirmam a ausência da percepção de vulnerabilidade à infecção entre os membros da equipe de enfermagem, em especial entre aqueles com longa experiência profissional, nos quais a resistência a mudanças expressa-se de maneira marcante, constituindo uma significativa barreira à adesão a tais práticas.

... é complicado a adoção das precauções
pelos funcionários com mais de 20 anos
de trabalho na instituição, querem continu-
ar fazendo o mesmo de quando foram ad-
mitidos, acham que não precisam mudar,
eles não aceitam e dizem: eu faço assim
há 20 anos e vou continuar fazendo por-
que para mim continua sendo bom!

A fala de uma das enfermeiras explicita que o trabalhador de enfermagem subestima seu potencial de vulnerabilidade à infecção, que está continuamente presente na prestação da assistência. O tempo de exercício profissional, ou seja, a experiência profissional parece ser um dos seus determinantes a indicar a credibilidade dos profissionais quanto ao sentimento de imunidade ou vulnerabilidade, como demonstrou estudo $^{(15)}$, onde os autores verificaram maior ocorrência de acidentes com materiais perfurocortantes nos profissionais que exercem suas funções há mais de dez anos. $\mathrm{Na}$ primeira etapa da análise desse estudo, os autores consideraram como um dos condicionantes da não-adesão às precauções/isolamento.

Você pergunta ao funcionário: há quanto tempo você trabalha aqui? Ele responde: Ah, estou aqui há uns dez anos! Você pergunta: e você não usa luvas? Ele responde: não, nunca tem luvas e nem precisa, eu sempre fiz assim e nunca peguei nada. Agora é que a senhora está querendo que a gente use!
Biossegurança em DST/AIDS:

condicionantes da adesão do trabalhador de enfermagem

às precauções 
Elucir Gir

Renata Ferreira Takahashi

Maria Amélia C. de Oliveira

Lucia lasuko Izumi Nichiata

Sueli Itsuko Ciosak
Um fator que se soma à percepção de invulnerabilidade é o incômodo provocado pelo uso de determinado equipamento por tempo prolongado, especialmente a máscara, indicada como um elemento dificultador restritivo.

... a adesão ao uso das máscaras é difícil, há resistência, porque ela é ruim, sufoca, tem que guardar após o seu uso.

A falta de credibilidade à eficácia das medidas de proteção, inclusive com relação aos equipamentos de proteção individual, associada às dificuldades de capacitação de pessoal, ao desrespeito às normas pré-estabelecidas e ao desinteresse do trabalhador são, segundo as informantes, as situações mais freqüentemente enfrentadas.

A mudança de práticas arraigadas é um objetivo difícil de ser atingido ${ }^{(16)}$, o que é confirmado no seguinte depoimento:

Treinar o pessoal é uma dificuldade grande, você procura incorporar conceitos novos, uma tecnologia nova, para funcionários com vinte anos de casa, que estão sempre fazendo a mesma coisa, é muito complicado.

Analisando as sete categorias de isolamento utilizadas na década de 70 , verificamos o estabelecimento de um conjunto de técnicas consideradas obrigatórias, com o intuito de diminuir o número de normas e rotinas para a prática do isolamento, facilitando, assim, a sua execução. Ao reexaminálas, constatamos que em certas categorias preconizavam-se medidas desnecessárias, contribuindo para o seu descrédito, na avaliação dos profissionais sobre sua operacionalização.

O trabalhador que não reconhece sua vulnerabilidade à infecção predispõe-se à exposição a patógenos, como exemplo, a situação em que o indivíduo utiliza os EPIs somente na prestação de assistência ao paciente cujo diagnóstico é conhecido, conforme podemos constatar no relato abaixo:

... só o paciente com aids tem isolamento,

há dois apartamentos para eles ...

Não há justificativa para a afirmação de que somente na assistência ao paciente com aids o profissional deve adotar medidas de proteção individual, face ao elevado percentual de pessoas infectadas pelo HIV/ aids que desconhecem o seu estado de soropositividade, como aponta a literatura.

Além disso, especialistas da área de ensino recomendam a inclusão do tema "biossegurança" tanto em cursos de graduação da área de saúde como nos de pós-graduação, atualização e em quaisquer outros eventos que abordem as doenças infecciosas.

O entendimento de que "somente o outro é vulnerável à infecção”, está presente tanto no profissional da saúde quanto na população em geral, como nos mostra a falta de uma das participantes “(...) isso não vai acontecer comigo".

Independentemente de situações de vulnerabilidade pessoal ou profissional, os resultados de algumas investigações com portadores de HIV/AIDS explicitaram as representações acerca da condição/estado de não-vulnerabilidade à infecção ${ }^{(16-18)}$.

Um outro determinante da subestimação da vulnerabilidade à infecção relaciona-se à falta de conhecimento sobre a magnitude das doenças profissionais causadas por agentes biológicos, como as hepatites $\mathrm{B}$ e $\mathrm{C}$, a tuberculose pulmonar e a infecção pelo $\mathrm{HIV}^{(6,19-20)}$.

A divergência sobre a adoção das precauções/isolamento no trato das doenças transmissíveis, no interior de instituições de saúde, resulta de falhas dos profissionais quanto ao conhecimento do mecanismo de transmissão e às características do agente causal de algumas delas. A compreensão incorreta dos fundamentos das precauções universais é citada por Brevidelli et al. ${ }^{(16)}$ como um dos motivos para o questionamento de alguns cuidados recomendados, como o não-reencape de agulhas se o paciente não tiver aids. Da mesma forma, em relação ao uso de luvas, que são utilizadas quando há conhecimento, a priori, do diagnóstico de aids.

O conhecimento correto acerca das vias de transmissão de agentes infecciosos possibilita a racionalização das medidas de isolamento, visando impedir a propagação dos patógenos e a redução de $\operatorname{custos}^{(14)}$.

A relação entre crenças e adesão às recomendações de medidas preventivas é determinada pelo tempo de exercício profissional do enfermeiro, inferior há 2 anos, pois são eles que percebem menor número de barrei- 
ras e maior número de benefícios. Portanto, o modelo de crenças em saúde demonstrou por que os profissionais de saúde não se previnem contra a aquisição de infecção via sanguínea, considerando essencialmente a aids, hepatites $\mathrm{B}$ e $\mathrm{C}$ como transmissoras ${ }^{(21)}$

Um outro aspecto relevante que constitui fator de interferência na prática do isolamento/precauções, identificado pelo grupo, diz respeito ao conhecimento heterogêneo da equipe multiprofissional, sendo muitas vezes incorreto, o que é evidenciado na fala a seguir:

\begin{abstract}
Por exemplo, entra uma meningite viral e o médico deixa prescrito isolamento respiratório. Nós sabemos que neste caso não há necessidade desse tipo de isolamento. Nós usamos as PP e as outras precauções por forma de transmissão. Pela fala já é possível detectar uma linguagem diferente da nossa. Aí, tem que ser feito todo um trabalho com esse profissional, que muitas vezes não aceita as mudanças
\end{abstract}

Eles querem colocar em isolamento todos os tipos de meningites, quando só a meningocócica é que necessita de um tipo de precauções; eles prescrevem isolamento quando não é necessário.

A deficiência na formação profissional do enfermeiro, no que tange à sua sensibilização para a prática de medidas de proteção individual também foi relatada como um determinante da atual prática de precauções/ isolamento. Um dos motivadores dessa deficiência, mencionado pelas participantes, foi a diversidade dos currículos dos cursos de graduação das Escolas de Enfermagem, pois as disciplinas que abordam a temática precauções/isolamento têm cargas horárias e programas diferentes, resultando em conhecimento insuficiente ou em equívocos de conceitos:

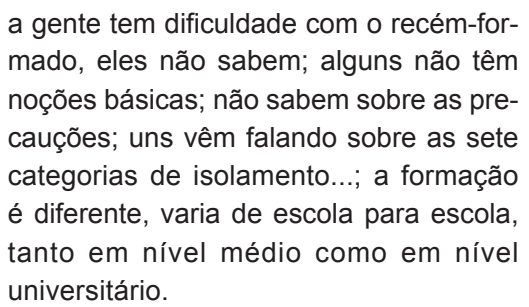
mado, eles não sabem; alguns não têm noções básicas; não sabem sobre as precauções; uns vêm falando sobre as sete categorias de isolamento...; a formação é diferente, varia de escola para escola, tanto em nível médio como em nível universitário.

Também o descompasso entre o ensino nas universidades e a prática nas instituições de saúde foi considerado a causa principal de práticas inadequadas de precauções/isolamento, haja vista a presença de barreiras até mesmo para seu ensino prático, como no caso de um trabalhador que fala com ironia ao professor:

... esses cuidados só a senhora e seus

alunos é que fazem..

Um outro aspecto que não se limita ao período de formação dos trabalhadores da enfermagem refere-se à sua sensibilização e motivação para a adoção dessas práticas. $\mathrm{O}$ questionamento sobre a incorporação de reformulações dos conceitos de isolamento nos currículos dos cursos de graduação em enfermagem é procedente, assim como a necessidade de integrá-los ao conjunto de disciplinas que envolvem a prática assistencial, e não apenas àquelas que abordam as doenças transmissíveis. Porém, é necessário que após o período de formação, o profissional participe de programas de educação continuada para prosseguimento do processo de conscientização acerca da sua vulnerabilidade às infecções e possibilitar a constituição de um veículo de disseminação de patógenos.

Os dados obtidos e analisados neste estudo mostram-se semelhantes aos encontrados em outras pesquisas feitas com base em diferentes referenciais teóricos. Fica evidente que o enfermeiros apresenta conduta ambivalente frente à situação de risco de contaminação pelo HIV, ora priorizando a sua auto-proteção, ora valorizando os cuidados de enfermagem ao cliente, em detrimento das normas de biossegurança e, conseqüentemente, negligenciando a si próprio ${ }^{(21-22)}$.

\section{CONSIDERAÇÕES FINAIS}

A análise dos dados permite-nos tecer algumas considerações que evidenciam pontos vulneráveis na abordagem da questão da prática de precauções/isolamento.

Entre as implicações da baixa adesão às precauções se destaca o aumento do risco da infecção hospitalar, quando o profissional atua como um agente propagador de infecção. Há uma implicação ética em sua conduta, pois o seu comportamento coloca em situação de risco aquele que é seu objeto do cuidado.

A subestimação da vulnerabilidade potencial de contaminação do pessoal da área da enfermagem, uma vez que existem instituições de saúde que não adotam as precauções-
Biossegurança em DST/AIDS:

condicionantes da adesão do trabalhador

de enfermagem

às precauções 
Elucir Gir

Renata Ferreira Takahashi Maria Amélia C. de Oliveira Lucia lasuko Izumi Nichiata Sueli Itsuko Ciosak padrão, associada às características das práticas evidenciam a necessidade de ampla divulgação das atuais recomendações sobre o isolamento/precauções. Essa divulgação deverá desencadear um processo de discussão local que contemple a abordagem da política institucional sobre a prevenção de riscos ocupacionais, as suas implicações para a qualidade da assistência e as questões subjetivas presentes na prática das precauções/isolamento.

As escolas de enfermagem do país devem instruir o estudante a desenvolver uma prática adequada do isolamento/precauções, através da inserção dessa temática nos cursos de graduação, pós-graduação senso latu e strictu, ou ainda, promovendo reuniões científicas para debate dessa problemática.

É de suma importância que as instituições de saúde definam e adotem uma política pública sobre precauções/isolamento para doenças transmissíveis, visando manter atualizadas as práticas de proteção ao trabalhador dessa área. Essa política deverá fundamentar-se nas informações epidemiológicas desse grupo de moléstias e na evolução do conhecimento técnico-científico.
Os resultados deste estudo suscitam a necessidade de intervenções efetivas que poderão incrementar o uso das precauções e dentre as intervenções destacamos a elaboração do diagnóstico situacional do uso dos EPI, realização de treinamento em serviço, divulgação de informações sobre o resultado da adoção das precauções e melhoria da disponibilidade de recursos materiais e humanos.

São desejáveis as parcerias entre instituições de ensino e assistenciais no sentido de promover ações efetivas de proteção à saúde do trabalhador, privilegiando a biossegurança, respaldada pelo senso de responsabilidade como um atributo individual e não como uma prática imposta.

A desconstrução da percepção de invulnerabilidade a infecções no exercício profissional deve ser trabalhada para que o comodismo e as práticas de risco sejam substituídos por comportamentos que resultem em assistência de qualidade ao usuário e na maior proteção possível ao trabalhador da saúde.

\section{REFERÊNCIAS}

(1) Carvalheiro JR. "Pestilências": velhos fantasmas, novas cadeias. Saúde Soc 1992; 1:25-42.

(2) Ministério da Saúde. Secretaria Nacional de Programas Especiais de Saúde. Divisão Nacional de Controle de Doenças Sexualmente Transmissíveis-SIDA/AIDS. Normas técnicas para prevenção da transmissão do HIV nos serviços de saúde. Brasília: Centro de Documentação; 1989.

(3) Peter G, editor. Red Book: report of committee on infections diseases. $23^{\text {th }}$ ed. ElkGrove Village: American Academy of Pediatrics; 1994. p. 93-115.

(4) Piqueras Altabella R, Pinazo Muria M, Martinez Ruiz MJ, González Monte C, Juan García S, Pérez Martín M. Exposicion accidental a sangre y fluidos corporales: riesgo asociado a maniobras de enfermeria. Rev Rol Enferm 1996; 19(209):21-8.
(5) Gershon RR, Vlahov D, Felknor SA, Vesley D, Johnson PC, Delclos GL et al. Compliance with universal precautions among health care workers at three regional hospitals. Am J Infect Control 1995; 23(4):225-36.

(6) CDC. Centers for Disease Control. Guidelines for prevention of transmission of human immunodeficiency virus and hepatitis B virus to health care and public safety workers. MMWR 1998; 38(65):1-17.

(7) CDC. Centers for Disease Control. Recommendations for prevention of HIV transmission in health care settings. MMWR 1988; 37:5-6.

(8) Do AN, Ciesielski CA, Metler RP, Hammett TA, Li J, Fleming PL. Ocupationally acquired human immunodeficienty vírus (HIV) infection: national case surveillance data during 20 years of the HIV epidemic in the United States. Infec Control Hosp Epidemiol 2003; 24(2):86-92. 
(9) Santos NJS, Monteiro ALC, Ruiz EAC. The first case of Aids due to ocupational exposure in Brazil. Braz J Inf Dis 2002; 6(3):140-1.

(10) Almeida MCP. A formação do enfermeiro frente à reforma sanitária. Cad Saúde Pública 1986; 2(4):505-10

(11) Carvalho MS. A vigilância epidemiológica e a infecção pelo HIV. Cad Saúde Pública 1989; $5(2): 160-8$

(12) Secretaria de Estado da Saúde. Isolamentos Hospitalares. São Paulo, 1991. (Informes Técnicos, 15).

(13) Bardin L. Análise de conteúdo. Trad. de Luis Antero Reto e Augusto Pinheiro. Lisboa: Edições 70; 1977.

(14) Garner JS. Guideline for isolation precautions in hospitals. The Hospital Infection Control Practices Advisory Committee. Infect Control Hosp Epidemiol 1996; 17(1):53-80.

(15) Gir E, Costa FPP, Silva AM. A enfermagem frente a acidentes de trabalho com material potencialmente contaminado na era do HIV. Rev Esc Enferm USP 1998; 32(3):262-72.

(16) Brevidelli MM, Assayag RE, Turcato Júnior G. Adesão às precauções universais: uma análise do comportamento de equipe de enfermagem. Rev Bras Enferm 1995; 48(3): 218-32.
(17) Gir E. Sexualidade e a mulher portadora do vírus da imunodeficiência humana tipo 1 (HIV-1). [livre-docência] Ribeirão Preto (SP): Escola de Enfermagem de Ribeirão Preto/ USP; 1997.

(18) Takahashi RF. A singularidade e a sociabilidade de vivenciar a "tuberculaids": a morte anunciada. [tese] São Paulo (SP): Escola de Enfermagem da USP; 1997.

(19) Marcus R, Bell DB. Occupational risk of human immunodeficiency virus infection in health care workers. In: De Vita VT, Hellman S, Rosenberg AS, editors. AIDS: etiology, diagnosis, treatment and prevention. $4^{\text {th }}$ ed. Philadelphia: Lippincott-Raven; 1997. p. 645-54.

(20) Atualidades em DST/AIDS: biossegurança. Secretaria de Estado da Saúde. Programa de DST/AIDS. São Paulo (SP) 1998; 1(1).

(21) Brevidelli MM, Cianciarullo TI. Aplicação do modelo de crenças em saúde na prevenção dos acidentes com agulha. Rev Saúde Pública 2001; 35(2):193-201.

(22) Almeida Filho AJ, Sauthier J. Liberdade e compromisso ético do enfermeiro frente às situações de risco de contaminação. Esc Anna Nery Rev Enferm 2000; 4(2):171-9.
Biossegurança em DST/AIDS:

condicionantes da adesão do trabalhador de enfermagem às precauções 